\title{
Anxiety disorders in people with learning disabilities
}

\author{
Sherva Elizabeth Cooray \& Alina Bakala
}

Abstract People with learning disabilities are much more vulnerable to psychiatric illnesses, and will increasingly be accessing generic services. Treatment and management of psychiatric disorders is problematic, primarily because of difficulties in diagnosis, since classificatory systems are standardised on people with average intellectual functioning. This article provides an overview of the clinical implications of anxiety disorders within the context of learning disability.

People with learning disabilities constitute $2 \%$ of the general population. They are a heterogeneous, psychosocially disadvantaged and vulnerable group with a relatively higher prevalence of mental disorders (Borthwick-Duffy, 1994). Despite difficulties in the diagnosis and classification of psychiatric illnesses in this population (Fryers, 1997) there is ample evidence that anxiety disorders do occur (McNally \& Ascher, 1987) and they are reported to be at least as common as in the general population, if not more so (King et al, 1994; Deb et al, 2001a).

The diagnosis, classification and management of mental disorders in people with learning disabilities are often fraught with challenges not encountered in people with average IQ. Within the context of the philosophies of normalisation, equity and social inclusion, health professionals are increasingly called upon to assess and treat learning-disabled individuals, often in crisis. Frequently, they exhibit challenging behaviour as a means of coping with frustration, anxiety and stress (Menalescino, 1977). It is therefore essential that all mental health professionals acquire the fundamental skills needed at the interface of learning disability and psychiatric disorders, underpinned where appropriate by access to specialist services. Here we explore these key issues and implications for clinical practice with relation to anxiety disorders.

Anxiety is a universal human experience. It is a distressing emotion, consisting of both psychological and somatic manifestations and hyperarousal. It is frequently accompanied by behavioural reactions (Hoen-Saric et al, 1995). At optimal levels it is normal, motivational and protective, helpful in coping with adversity (the Yerkes-Dodson law; Yerkes \& Dodson,
1906). Anxiety differs from fear, in that fear is a focused and direct response to a specific event or object that the person is consciously aware of. The DSM-IV-TR defines anxiety as:

'the apprehensive anticipation of future danger or misfortune accompanied by a feeling of dysphoria or somatic symptoms of tension. The focus of anticipated danger may be external or internal' (American Psychiatric Association, 2000).

Anxiety disorder, or pathological anxiety, occurs when the intensity or duration of anxiety is disproportionate to the potential for harm, or in the absence of recognisable threat to the individual. It involves increased levels of arousal, which has the effect of disorganising rather than facilitating an individual's performance.

\section{Prevalence}

Anxiety ranks among the most common categories of mental disorder reported in large-scale epidemiological studies within the general population (Robins \& Regier, 1991); Jenkins, 1997). In primary care, anxiety and depression account for $80 \%$ of consultations for mental health problems (Cooper, 1972). Untreated, they are costly to both the individual and society. Comorbidity is also a significant problem: about $75 \%$ of individuals with an anxiety disorder meet criteria for at least one comorbid psychiatric disorder (Kessler et al, 1994).

In people with learning disabilities anxiety disorders are well recognised (Bailey \& Andrews, 2003), may be underreported (Reiss et al, 1982) and underdiagnosed (Veerhoven \& Tuinier 1997). In a

Sherva Cooray is a consultant psychiatrist and lead clinician in the psychiatry of learning disability with Brent Teaching Primary Care Trust (Kingsbury Hospital, Honeypot Lane, London NW9 9QY, UK. E-mail: cooray@medimail.net) and an honorary senior lecturer at Imperial College School of Medicine, London. Alina Bakala is a specialist registrar, also at Kingsbury Hospital. 
sample of learning-disabled people, Cooper (1997) found higher rates of anxiety disorders in the elderly individuals than in the younger age groups. A study cohort comparing people with learning disabilities with the general population revealed significantly higher rates of phobic disorder in the former (Deb et al, 2001a). A literature review (Raghavan, 1997) revealed a similar if not higher prevalence of generalised anxiety disorder in people with learning disabilities. Significant comorbidity was also reported in a study by Masi et al (2000) in learningdisabled adolescents. Anxiety disorders were identified as more prevalent in individuals with selfinjurious behaviour than in those without such behaviour (Moss et al, 2000).

\section{Diagnosis and classification}

Anxiety disorders include panic disorder, agoraphobia, specific phobias, generalised anxiety disorder, social phobia, obsessive-compulsive disorder, and acute and post-traumatic stress disorders (PTSD). Accurate diagnosis is central to the effective management of these conditions (Box 1). Frequently, comorbid disorders such as depression can make the presentation and diagnosis confusing, even in the general population.

Sovner (1986) highlighted four factors reflecting the profound biopsychosocial effects of learning disability that may influence the diagnostic process:

- intellectual distortion - emotional symptoms may be difficult to elicit because of deficits in abstract thinking and in receptive and expressive language skills; for example the phrase 'butterflies in the stomach' might not be understood;

- psychosocial masking - limited social experiences can influence the content of psychiatric symptoms; for example mania may present as a grandiose belief that the individual can drive a car;

- cognitive disintegration - a decreased ability to tolerate stress can lead to anxiety-induced decompensation (sometimes misinterpreted as psychosis);

- baseline exaggeration - the severity or frequency of chronic maladaptive behaviour may increase after onset of psychiatric illness.

Another factor that may contribute to difficulties experienced by clinicians is diagnostic overshadowing, a tendency in the clinician to overlook symptoms of mental illness, attributing them to learning disability (Reiss et al, 1982).

In people with learning disabilities, the clinical utility of the ICD-10 and DSM- IV-TR in diagnosing
Box 1 Difficulties of psychiatric diagnosis in people with learning disabilities

- Current psychiatric classification systems are based on studies that excluded people with learning disabilities

- Deficits in language and/or abstract thinking make emotional symptoms difficult to identify

- Limited social experience can influence the content of psychiatric symptoms

- There is a tendency for clinicians to overlook psychiatric symptoms, attributing them to learning disability

anxiety disorders is limited (Ruedrich et al, 2001; Cooray et al, 2005). This is because diagnostic criteria are firmly entrenched in language-based phenomenology, validated on individuals with average intellectual functioning. Currently, the evidence base relating to anxiety disorders in people with learning disabilities is poor, further compounded by difficulties in carrying out robust research (Oliver et al, 2003). Most studies use some form of modified criteria, with a resultant lack of consistency.

Endeavours to improve diagnostic practice have led to the development of guidelines (Rush \& Frances, 2000; Deb et al, 2001b) and a number of informant and self-report assessment instruments of psychopathology, some of which are listed in Box 2. However, the reliability of these instruments is variable. Costello et al (1997) reported that the greatest unreliability when applying the PAS-ADD related to symptoms of anxiety.

To address the problems of classification, a new consensus-based system reflecting expert opinion, the Diagnostic Criteria for Psychiatric Disorders for Use with Adults with Learning Disabilities/Mental

Box 2 Instruments for detecting psychopathology in learning disability

- Psychopathology Instrument for Mentally Retarded Adults (PIMRA), based on DSMIII-R (Matson et al, 1984)

- Diagnostic Assessment for the Severely Handicapped (DASH) scale, based on DSMIII-R (Matson et al, 1991)

- Psychiatric Assessment Scale for Adults with Developmental Disability (PAS-ADD), based on ICD-10 (Moss et al, 1993) 
Retardation (DC-LD), has been developed (Royal College of Psychiatrists, 2001). This provides operationalised diagnostic criteria for psychiatric disorders for use with adults with moderate, severe or profound learning disabilities. It may also be used to complement the ICD-10 or DSM-IV-TR in adults with mild learning disabilities.

Generally, all criteria for anxiety disorders in ICD-10 or DSM-IV-TR can be applied validly and reliably in people with mild-to-moderate learning disability (Masi et al, 2002; Stavrakaki, 2002). In those with severe-to-profound disability, psychiatric assessments must be modified within the context of limitations in cognitive function, using simple spoken language, pictures and sign language. Collateral information from a primary caregiver familiar with the individual is essential. The interview must be unhurried, allowing sufficient time to give an account of events. Questions and responses may need to be repeated and rechecked. People with learning disabilities are suggestible and when presented with a choice of alternatives may agree or repeat the last words of the questionner's sentence. Consequently, leading questions must be avoided.

\section{Effects of learning disability on the presentation of the clinical features of anxiety}

The clinical features of anxiety have cognitive, physiological, psychological and behavioural components. Psychological and cognitive elements may present as fearful anticipation, irritability, concentration and memory problems, repetitive worrying thoughts, fear and, in extreme instances, fully fledged panic. Physiological manifestations include dry mouth, difficulty in swallowing, flushing, sweating, pallor, palpitations, tremor, hyperventilation, chest pain/tightness, headache, backache, fatigue, muscle tension, diarrhoea, increased urinary frequency, paraesthesia, heightened startle response and insomnia. Avoidance is a common behavioural manifestation of anxiety. Chronologically, anxiety can be episodic, continuous or stress related.

Descriptions of key diagnostic concepts of anxiety require a certain level of IQ and linguistic skills, particularly with relation to more complex subjective cognitive phenomena. Matson et al, 1997 concluded that when anxiety cannot be expressed, especially in people with more severe degrees of learning disability, it might manifest as a behavioural disorder. However, this may be non-specific and may be a reflection of other triggers such as the
Table 1 Behavioural correlates of anxiety symptoms in learning disability

\begin{tabular}{|c|c|}
\hline Anxiety symptom & Behavioural correlate \\
\hline Dry mouth & Increased drinking \\
\hline $\begin{array}{l}\text { Sensations of shortness } \\
\text { of breath }\end{array}$ & Hyperventilation \\
\hline Sensations of anxiety & $\begin{array}{l}\text { Signs of increased } \\
\text { arousal (shortness of } \\
\text { breath; increased pulse } \\
\text { rate); irritability; anger; } \\
\text { sweating; self-injurious } \\
\text { behaviour; avoidance } \\
\text { behaviour }\end{array}$ \\
\hline Panic & $\begin{array}{l}\text { Tremulousness with } \\
\text { excessive motor activity, } \\
\text { agitation and or aggression } \\
\text { (Stavrakaki, 2002) }\end{array}$ \\
\hline
\end{tabular}

environment. It is important to distinguish between behavioural disorders and abnormal behaviours that are the result of an underlying mental illness. In diagnosising anxiety, Khreim \& Mikkelson (1997) highlighted the need to place relatively greater emphasis on phenomena such as agitation, screaming, crying, withdrawal, regressive/clingy behaviour or freezing, all of which could be interpreted as manifestations of fear.

In people with severe and profound learning disability, subjective elements of the diagnostic criteria for anxiety are difficult, if not impossible, to apply. The clinician must therefore rely on signs (observed behaviours) rather than on self-reported distress and on the diagnosis postulated from observations made by primary caregivers. The application of objective equivalents in lieu of subjective criteria, as well as unofficial pragmatic modifications to the DSM and ICD classificatory systems, may be justifiable in such instances. This has prompted clinicians to interpret diagnostic criteria in terms of behavioral correlates that reflect the verbal components of the relevant anxiety disorders (Table 1).

These issues might best be addressed by the official modification of the DSM and ICD diagnostic criteria for anxiety to tailor them to adults with learning disabilities, as has already been done for the child and adolescent population.

\section{Risk factors}

People with learning disabilities frequently contend with a lifetime of adversity, inadequate social supports and poor coping skills. These factors contribute to increased vulnerability to stressful life events, which may trigger anxiety disorders. 
Kessler et al (1994) reported that all types of mental disorder, including anxiety, decline with increasing educational level. Current psychological models of anxiety tend to incorporate the role of the individual's vulnerability, which includes both genetic (Smoller \& Tsuang, 1998; Kendler et al, 2001) and acquired predispositions (Coplan et al, 1997). Some genetic causes of learning disability have associations with anxiety, for example: fragile- $X$ syndrome is associated with social anxiety disorder; Rubinstein-Taybi and Prader-Willi syndromes with obsessive-compulsive disorder (Levitas \& Reid, 1998); and Williams syndrome with anxiety (Einfeld et al, 2001) and phobias (Dykens, 2003). Hyman et al (2002)noted significantly high compulsive behaviour in Cornelia de Lange syndrome.

Studies on types of fear reported in this population demonstrate similarities between children and adults of equivalent mental age, highlighting the developmental perspective (Sternlicht, 1979; Duff, 1981; Pickersgill et al, 1994). For example individuals with moderate learning disability experience fears of: animals, thunder and ghosts (preoperational thinking), and physical injuries (concrete operational), mirroring normal Piagetian transition in non-learning disabled children. However, in childhood, anxieties and phobias might also occur as transient phenomena, integral to normal early development.

The psychological basis underpinning anxiety includes psychodynamic (anxiety perceived as an expression of unresolved conflict), cognitive (role of individual's perceptions of stressful events in aetiology of anxiety) and behavioural (role of learning, e.g. through classical conditioning and vicarious or observational learning) theories. Ingram et al (1998) reported that people with anxiety frequently have negative cognitions.

\section{Treatment}

The treatment for anxiety disorders in people with learning disabilities broadly parallels that in the rest of the population (Box 3). A range of effective interventions is available (Stavrakaki, 1997), including medication (Kapczinski et al, 2004), psychological therapies (reassurance, counselling, anxiety management such as relaxation training, anger management and self-help such as bibliotherapy). Desensitisation and exposure therapy are effective management strategies in obsessivecompulsive disorder and social phobia. Some studies suggest that optimum results are achieved by combining psychological and pharmacological interventions (Fineberg \& Drummond, 1995; Kandel, 1999). Behavioural therapy and cognitive therapy alone or in combination have demonstrated clear experimental evidence of efficacy in the treatment of anxiety disorders (Michels, 1997). Involving affected individuals in an effective partnership with healthcare professionals and using comprehensible and clear communication both improve outcomes (National Institute for Clinical Excellence, 2004).

In people with mild or borderline learning disability and anxiety disorders, evidence based on case studies demonstrates the effectiveness of cognitive-behavioural therapy (Lindsay et al, 1997; Lindsay, 1999). The core principles of cognitive

\section{Box 3 Case example}

A.M., a 29-year-old man with moderate learning disabilities and Down's syndrome (trisomy chromosome 21) was taken to his local accident and emergency department in a distressed and agitated state, having physically attacked his paid carer during a community trip in a car. Once in the hospital he presented as calm and appropriate in his behaviour.

He was initially unable to give an explanation of his earlier distress, but it was elicited from him that he had a 2-year history of becoming nervous in certain situations, for example while travelling, particularly on long car journeys. He would worry about being involved in an accident and being unable to escape from the vehicle. Although not describing subjective feelings of 'anxiety', on direct questioning, he reported experiencing autonomic symptoms of anxiety at such times, including sweating, tremor and palpitations. He denied persistently depressed mood, and did not have any biological features of a mood disorder.

Collateral history was obtained from his mother. It transpired that the onset of his anxiety symptoms correlated with a number of bereavements of significant people in his life over the previous 4 years. Moreover, he had become so nervous in social situations that he was living an extremely restricted lifestyle, avoiding such situations. He had never previously experienced a panic attack.

Panic disorder with agoraphobia was diagnosed. A referral was made to the local learning disability psychiatric team. A.M. was reluctant to take medication (a selective serotonin reuptake inhibitor), but engaged successfully with psychological treatment of his anxiety disorder. 


\section{Box 4 Learning points}

- People with learning disabilities increasingly access generic services for assessment and treatment of psychiatric disorders

- Anxiety disorders are at least as common, and probably more common, among people with learning disabilities as among the general population

- Owing to heterogeneity of abilities and communication skills in people with learning disabilities, it is difficult to use a single standardised criterion for psychiatric diagnosis across the whole spectrum

- All the criteria for anxiety disorders in ICD10 and DSM-IV can be applied validly and reliably in people with mild-to-moderate learning disability, but behavioural equivalents may be more appropriate in severe learning disability

- Management and treatment parallel those used for the general population

therapy may require modification to meet the abilities of the individual. Evidence relating to the long-term outcome of these interventions is unavailable, although they are likely to be beneficial.

Training and education in relaxation techniques is also helpful for those with mild, moderate or severe learning disability. Martin et al (1998) reported a successful outcome with relation to achieving relaxation in individuals with severe-to-profound learning disability using multisensory stimulation (Snoezelen environment).

The pharmacological treatment of anxiety, targeted at achieving maximum gains from the lowest effective dose and with minimum adverse effects include selective serotonin reuptake inhibitors (SSRIs), serotonin noradrenalin reuptake inhibitors (SNRIs), buspirone, beta-blockers, benzodiazepines and tricyclic antidepressants. People with learning disabilities may not be able to report adverse effects. Any resultant impairment of cognitive and psychomotor abilities may have profound implications for behaviour and general functioning.

In view of their potential adverse effects benzodiazepines should be considered only for short-term (no more than 4 weeks) treatment of acute, disabling anxiety which is causing significant distress, while medium- or long-term strategies are instituted. A minority with intractable anxiety may benefit from long-term treatment, which should not be denied (Royal College of Psychiatrists, 1997).
In generalised anxiety disorder, obsessivecompulsive disorder, panic disorder, PTSD and social phobia, SSRIs may be used as first-line treatment. Treatment with SNRIs such as venlafaxine, which is effective in generalised anxiety disorder, should be supervised by specialist mental health medical practitioners. Tricyclics may be used as second-line intervention for all of these conditions with the exception of social phobia. Other pharmacological treatments with a weaker evidence base or which are less well tolerated include buspirone (generalised anxiety disorder, obsessive-compulsive disorder) and antipsychotics (quetiapine or risperidone as antidepressant augmentation for obsessive-compulsive disorder). The choice of treatment ultimately should be a consequence of the assessment process and shared decision-making, with emphasis on safety, tolerability and the patient's preferences within the context of best available evidence.

\section{Key points}

Box 4 summarises key learning points to be taken from this article.

\section{References}

American Psychiatric Association (2000) Diagnostic and Statistical Manual of Mental Disorders (4th edn, Text Revision) (DSM-IV-TR). Washington, DC: APA.

Bailey, N. M. \& Andrews, T. M. (2003) Diagnostic Criteria for Psychiatric Disorders for Use with Adults with Learning Disabilities/Mental Retardation (DC-LD) and the diagnosis of anxiety disorders. Journal of Intellectual Disability Research, 47 (suppl. 1), 50-61.

Borthwick-Duffy, S. A. (1994) Epidemiology and prevalence of psychopathology in people with mental retardation. Journal of Consulting and Clinical Psychology, 62, 17-27.

Cooper, B. (1972) Clinical and social aspects of chronic neurosis. Proceedings of the Royal Society of Medicine, 65, 509-512.

Cooper, S. A. (1997) Psychiatry of elderly compared to younger adults with intellectual disability. Journal of Applied Research in Intellectual Disability, 10, 303-311.

Cooray, S. E., Cooper, S.-A., Gabriel, S., et al (2005) Anxiety disorders. In NADD Diagnostic Manual (DSM-IV-ID) (eds R. Fletcher, E. Loschen, C. Stavrakaki, et al). Kingston, NY: NADD Press. In press.

Coplan, J. D., Pine, D. S., Papp, L. A., et al (1997) A view on noradrenergic, hypothalamic-pituitary-adrenal axis and extrahypothalamic corticotrophin-releasing factor function in anxiety and affective disorders: the reduced growth hormone response to clonidine. Psychopharmacology Bulletin, 33, 193-204.

Costello, H., Moss, S., Prosser, H., et al (1997) Reliability of the ICD 10 version of the Psychiatric Assessment Schedule for adults with developmental disability (PAS-ADD). Social Psychiatry and Psychiatric Epidemiology, 32, 339-343.

Deb, S., Thomas, M. \& Bright, C. (2001a) Mental disorder in adults with intellectual disability. I: Prevalence of functional psychiatric illness among a community-based population aged between 16 and 64 years. Journal of Intellectual Disability Research, 45, 495-505.

Deb, S., Matthews, T., Holt, G., et al (2001b) Practice Guidelines for the Assessment and Diagnosis of Mental Health Problems in Adults with Intellectual Disability. Brighton: Pavilion. 
Duff, R., La Rocca, J., Lizzet, A., et al (1981) A comparison of the fears of mildly retarded adults with children of their mental age and chronological age matched controls. Journal of Behavioural Therapy and Experimental Psychology, 12, 121124.

Dykens, E. M. (2003) Anxiety, fears, and phobias in persons with Williams syndrome. Developmental Neuropsychology, 23 , 291-316.

Einfeld, S. L., Tonge, B. J. \& Rees, V. W. (2001) Longitudinal course of behavioural and emotional problems in Williams syndrome. American Journal of Mental Retardation, 106 73-81.

Fineberg, N. \& Drummond, L. M. (1995) Anxiety disorders: drug treatment or behavioural cognitive psychotherapy. CNS Drugs, 3, 448-466.

Fryers, T. (1997) Epidemiology in relation to community and residential services. Current Opinion in Psychiatry, 10, 340-353.

Hoen-Saric, R., Borkovec, T. D. \& Nemiah, J. C. (1995) Generalized anxiety disorder. In Treatments of Psychiatric Disorders (2nd edn) (ed. G. O. Gabbard), pp. 1537-1567. Washington, DC: American Psychiatric Press.

Hyman, P., Oliver, C. \& Hall, S. (2002) Self-injurious behavior, self-restraint, and compulsive behaviors in Cornelia de Lange syndrome. American Journal on Mental Retardation, 107 146-154.

Ingram, R. E., Miranda, J. \& Segal, Z. V. (1998) Cognitive Vulnerability to Depression. New York: Guilford Press.

Jenkins, R., Lewis, G., Bebbington, P., et al (1997) The National Psychiatric Morbidity Surveys of Great Britain - initial findings from the household survey. Psychological Medicine, 27, 775-789.

Kandel, E. R. (1999) Biology and the future of psychoanalysis: A new intellectual framework for psychiatry revisited American Journal of Psychiatry, 156, 505-524.

Kapczinski, F., Lima, M. S., Souza, J. S., et al (2003) Antidepressants for generalized anxiety disorder. The Cochrane Database of Systematic Reviews, issue 2. Oxford: Update Software.

Kendler, K. S., Neale, M. C., Kessler, R. C., et al (1992) Major depression and generalized anxiety disorder. Same genes, (partly) different environment? Archives of General Psychiatry, 49, 716-722

Kessler, R. C., McGonagle, K. A., Zhao, S., et al (1994) Lifetime and 12-month prevalence of DSM-III-R psychiatric disorders in the United States. Results from the National Comorbidity Survey. Archives of General Psychiatry, 51, 8-19.

Khreim, I. \& Mikkelson, E. (1997) Anxiety disorders in adults with mental retardation. Psychiatric Annals, 27, 271-281.

King, B. H., DeAntonio, C., McCracken, J. T., et al (1994) Psychiatric consultation in severe and profound menta retardation. American Journal of Psychiatry, 151, 1802-1808.

Levitas, A. S. \& Reid, C. S. (1998) Rubinstein-Taybi syndrome and psychiatric disorders. Journal of Intellectual Disability Research, 42, 284-292.

Lindsay, W. R. (1999) Cognitive therapy. The Psychologist, 12, 238-241.

Lindsay, W., Neilson, C. \& Lawrenson, H. (1997) Cognitivebehaviour therapy for anxiety in people with learning disabilities. In Cognitive-Behaviour Therapy for People with Learning Disabilities (eds B. Stenfert Kroese, D. Dagnan \& K. Loumides), pp. 124-140. London: Routledge.

McNally, R. J. \& Ascher, L. M. (1987) Anxiety disorders in mentally retarded people. In Anxiety and Stress Disorders. Cognitive/Behavioural Assessment and Treatment (eds L. Michelson \& M. L. Ascher), pp. 379-394. New York: Guildford Press.

Martin, N. T., Gaffan, E. A. \& Williams, T. (1998) Behavioural effects of long-term multi-sensory stimulation. British Journal of Clinical Psychology, 37, 69-82.

Masi, G., Favilla, L. \& Mucci, M. (2000) Generalised anxiety disorder in adolescents and young adults with mild mental retardation. Psychiatry, 63, 54-64.

Masi, G., Brovedani, P., Mucci, M., et al (2002) Assessment of anxiety and depression in adolescents with menta retardation. Child Psychiatry and Human Development, 32, 227-237.
Matson, J. L., Kazdin, A. E. \& Senatore, V. (1984) Psychometric properties of the Psychopathology Inventory for Mentally Retarded Adults. Applied Research in Mental Retardation, 5 , $881-889$.

Matson, J. L, Gardner, W. I., Coe, D. A., et al (1991) A scale for evaluating emotional disorders in severely and profoundly mentally retarded persons. Development of the Diagnostic Assessment for the Severely Handicapped (DASH) scale. British Journal of Psychiatry, 159, 404-409.

Matson, J. L., Smiroldo, B. B., Hamilton, M., et al (1997) Do anxiety disorders exist in persons with severe and profound retardation? Research in Developmental Disabilities, 18, 39 44

Menalescino, F. J. (1977) Challenges in Mental Retardation. Progressive Ideology and Services. New York: Human Services Press.

Michels, R. (1997) Psychotherapeutic approaches to treatment of anxiety and depressive disorders. Journal of Clinical Psychiatry, 58 (suppl. 13), 30-32.

Moss, S., Ibbotson, B., Prosser. H., et al (1997) Validity of the PAS-ADD for detecting psychiatric symptoms in adults with learning disability (mental retardation). Social Psychiatry and Psychiatric Epidemiology, 32, 344-354.

Moss, S., Patel, P., Prosser, H., et al (1993) Psychiatric morbidity in older people with moderate and severe learning disability. I: Development and reliability of the patient interview (PAS-ADD). British Journal of Psychiatry, 163 471-480.

Moss, S., Emerson, E., Kiernan, C., et al (2000) Psychiatric symptoms in adults with learning disability and challenging behaviour. British Journal of Psychiatry, 17, 452-456.

National Institute for Clinical Excellence (2004) Anxiety: Management of Anxiety (Panic Disorder, with or without Agoraphobia, and Generalised Anxiety Disorder) in Adults in Primary, Secondary and Community Care (Clinical Guideline 22). London: NICE.

Oliver, P. C., Piachaud, J., Done, D. J., et al (2003) Difficulties developing evidence-based approaches in learning disabilities. Evidence-Based Mental Health, 6, 37-39.

Pickersgill, M. J., Valentine, J. D., May, R., et al (1994) Fears in mental retardation. Part 1 . Types of fears reported by men and women with and without mental retardation. Advances in Behaviour Research Therapy, 16, 277-296.

Raghavan, R. (1997) Anxiety disorders in people with learning disabilities: a review of the literature. Journal of Learning Disabilities for Nursing, Health and Social Care, 2, 3-9.

Reiss, S. \& Aman, M. G. (eds) (1998) Psychotropic Medication and Developmental Disabilities: The International Consensus Handbook. Columbus, OH: Ohio State University, Nisonger Center.

Reiss, S., Levitan, G. W. \& Szyszko, J. (1982) Emotional disturbance and mental retardation: diagnostic overshadowing. American Journal of Mental Deficiency, 86, 567574.

Robins, L. N. \& Regier, D. A. (1991) Psychiatric Disorders in America. The Epidemiologic Catchment Area Study. New York: Free Press.

Royal College of Psychiatrists (1997) Benzodiazepine: Risks, Benefits and Dependence. A Re-evaluation (Council Report CR59). London: Royal College of Psychiatrists.

Royal College of Psychiatrists (2001) DC-LD [Diagnostic Criteria for Psychiatric Disorders for use with Adults with Learning Disabilities/Mental Retardation] (Occasional Paper OP48) London: Gaskell.

Ruedrich, S. L. \& DesNoyers Hurley, A. (2001) Diagnostic uncertainty. Mental Health Aspects of Developmental Disabilities, 4, 43-46.

Rush, A. J. \& Frances, A., (eds) (2000) Expert consensus guideline series: treatment of psychiatric and behavioural problems in mental retardation. American Journal on Mental Retardation, 105 (3) (special issue), 159-226.

Smoller, J. W. \& Tsuang, M. T. (1998) Panic and phobic anxiety: defining phenotypes for genetic studies. American Journal of Psychiatry, 155, 1152-1162.

Sovner, R. (1986) Limiting factors in the use of DSM-III criteria with mentally ill/mentally retarded persons. Psychopharmacology Bulletin, 22, 1055-1059. 
Stavrakaki, C. (1997) Anxiety disorders in persons with mental retardation: diagnostic, clinical and treatment issues. Psychiatric Annals, 27, 182-189.

Stavrakaki, C. (2002) The DSM-IV and how it applies to persons with developmental disabilities. In Dual Diagnosis: An Introduction to the Mental Health Needs of Persons with Developmental Disabilities (eds D. Griffiths, C. Stavrakaki \& J. Summers), pp. 115-149. Ontario: Habilitative Mental Health Resource Network.

Sternlicht, M. (1979) Fears of institutionalised mentally retarded adults. Journal of Psychology, 101, 57-71.

Veerhoven, W. M. A. \& Tuinier, S. (1997) Neuropsychiatric consultation in mentally retarded patients. European Psychiatry, 12, 242-248.

World Health Organization (1992) The ICD-10 Classification of Mental and Behavioural Disorders: Clinical Descriptions and Diagnostic Guidelines. Geneva: WHO.

Yerkes, R. M. \& Dodson, J. D. (1906) The relation of strength of stimulus to rapidity of habit formation. Journal of Comparative Neurology and Psychology, 18, 459-482.

\section{MCQs}

1 With regard to people with learning disabilities:

a a diagnosis of learning disability is dependent on significantly sub-average IQ and associated deficits in adaptive behaviour with onset occurring before 18 years of age

$\mathrm{b}$ the prevalence of learning disability in the general population is $0.2 \%$

c mental health problems are less common than in the general population

d mental health problems always present as challenging behaviour

e the philosophy of normalisation supports people with learning disabilities accessing generic health services.
2 The following contribute to difficulties in psychiatric diagnosis in learning disability:

a diagnostic overshadowing

b limitations in the patient's linguistic skills

c the patient's suggestibility

d limitations in the patient's social experience

e absence of collateral information.

3 Anxiety disorders in people with learning disabilities: a are more common than in the general population

$\mathrm{b}$ are underdiagnosed in comparison with the general population

c are less likely to be comorbid with other psychiatric disorders than in the general population

$\mathrm{d}$ can only be diagnosed using modified diagnostic criteria

e do not respond to psychological treatments.

4 Anxiety is a common association in the following disorders:

a fragile- $X$ syndrome

b Downs syndrome

c autistic-spectrum disorder

d Williams syndrome

e Angelmans syndrome.

5 The following are features of severe anxiety:

a palpitations

b disorientation in place

c paraesthesia

d visual hallucinations

e obsessional symptoms.

\section{MCQ answers}

\begin{tabular}{|c|c|c|c|c|}
\hline & 2 & 3 & 4 & 5 \\
\hline $\mathrm{T}$ & a $\mathrm{T}$ & a $\mathrm{T}$ & a $\mathrm{T}$ & a $\mathrm{T}$ \\
\hline $\mathrm{F}$ & b $\mathrm{T}$ & b $\mathrm{T}$ & $b F$ & b F \\
\hline $\mathrm{F}$ & c $\mathrm{T}$ & C F & c $\mathrm{T}$ & \\
\hline $\mathrm{F}$ & $\mathrm{d} T$ & d F & $\mathrm{d} \mathrm{T}$ & \\
\hline $\mathrm{T}$ & e $\mathrm{T}$ & e $F$ & e F & e \\
\hline
\end{tabular}

